


\section{Carbon Capture Utilization and Storage (CCUS) in Tight Gas and Oil Reservoirs}

Pål Østebø Andersen , Bergit Brattekås , Yingfang Zhou, Paul Nadeau, Anders Nermoen , Zhixin Yu, Ingebret Fjelde , Eric Oelkers

University of Stavanger (Norway)

University of Bergen (Norway)

University of Aberdeen (Scotland)

NORCE Energy (Norway)

University College London (UK)

*Managing Guest Editor (E-mail: pal.andersen@uis.no)

\section{Introduction}

This special issue was compiled with the aim of advancing research of carbon capture utilization and storage (CCUS) in tight reservoirs. Tight reservoirs are typically composed of organic rich shaley rock-types that due to burial and heating have matured to produce hydrocarbon. With very low porosity and permeability the matured hydrocarbon did not migrate, but remained trapped in the source rock. Due to the poor flow properties of these rocks the hydrocarbons are recovered in unconventional ways, and thus termed unconventional resources. Specialized solutions are needed to induce a hydrocarbon flow rate sufficient for the operation to be economically viable. This is typically done by hydraulic fracturing, where hydraulic fractures are induced by the injection of fluids, and, further held open by proppants (sand/ceramic pellets) to allow the oil and gas to flow back into the well (Holditch 1982). Typically, production and stimulation are performed from individual wells. The volume where hydraulic and opened natural fractures has increased the effective permeability is referred to as the stimulated reservoir volume and is where production mainly occurs. Since the lateral extent of the hydraulic fractures are constrained, more wells are required for unconventional sources. Although multistage hydraulic fracturing in combination with horizontal wells has revolutionized production from tight reservoirs, the recovery factors are often as low as 5 to $10 \%$ (see e.g. Seales et al. 2017). As such, there is a large gap between the ultimate resource potential and the recoverable reserves and thus a significant potential for techniques such as $\mathrm{CO}_{2}$ and other innovative injection fluids to enhance oil and gas recovery.

Oil and gas extraction from tight rocks pose challenges that require technological developments. Fractures close over time as pore pressure is reduced and proppants gradually get squeezed. Further, the 'fracking' technology ha s been challenged related to the a) fate of injected fluids and to what extent the fractures propagate into surrounding formations and ground water; $b$ ) treatment of back-produced fluids and the safe storage of back-produced chemicals; c) land use, resources and de-forestation required to facilitate drilling of sufficient wells and construct roads for truck transport of frac-fluids; d) pipe-lines needed to transport produced oil and gas to the costumers may impact wild-life and pose leakage risks to water streams; and e) energy required to produce the unconventional hydrocarbons exceeds the energy needed for conventional production. By injecting more favorable injection fluids in more intelligent ways, one may be able to address both environmental and economic concerns.

It is agreed that atmospheric release of anthropogenic $\mathrm{CO}_{2}$ from e.g. production and burning of fossil fuels contributes to climate change and a warmer atmosphere. The consequences to different countries and regions vary significantly. So do the capabilities of different societies 
to adapt. The Paris agreement states that climate changes pose a threat to human societies and several ecosystems in nature. At the same time, the world needs access to cheap, reliable energy, especially developing countries where economic growth has most value. Further, having domestic sources of oil and gas is a great strategic asset for any country. To turn tight reservoir resources into available reserves, there is a need for scientific and technological developments that can enable a profitable production of energy, with little or no release of $\mathrm{CO}_{2}$.

Science, technology, economy, public opinion and policymaking must act together to handle the carbon storage / hydrocarbon recovery problem. One must determine 1) to what extent injected $\mathrm{CO}_{2}$ affects hydrocarbon production and how much $\mathrm{CO}_{2}$ remains stored, and, 2) cost incentives to operate both during the enhanced oil recovery (EOR) phase and further into the storage phase. A great advantage is that tight reservoirs can store massive amounts of $\mathrm{CO}_{2}$ by adsorption and residual trapped gas, resulting in little back-production of injected $\mathrm{CO}_{2} \cdot \mathrm{CO}_{2}$ has been shown to enhance both the methane gas extraction potential (by competitive adsorption leading to methane desorbing from the surface) and boost the oil recovery rate from tight rocks. Utilizing $\mathrm{CO}_{2}$ can then increase the recoverable amounts, which better utilizes the land, construction and surface facilities, and the rate at which hydrocarbons are produced. The potential to store $\mathrm{CO}_{2}$ in tight rocks during or after EOR operations is also at an extent that the concept of green oil exists; whereby even after the produced hydrocarbons are used, more $\mathrm{CO}_{2}$ is trapped underground than released.

The price the oilfield operator is willing to pay for $\mathrm{CO}_{2}$ is limited mainly by the efficiency of the injected $\mathrm{CO}_{2}$ to enhance oil recovery, and the price of the produced oil. In several fields in the US and in the Bati Raman oil field in Turkey, the use of $\mathrm{CO}_{2}$ found in natural gas deposits is cheaper and preferred over anthropogenic sources. However, $\mathrm{CO}_{2}$ capture from industrial processes such as steel and cement production, refineries, coal- and gas fired power plants, etc. is a proven technology with high technological readiness level and can contribute to shale CCUS operations. Experience of implementing $\mathrm{CO}_{2}$ capture from e.g. the coal fired power plant Boundary Dam (Canada) has shown that dramatic cost reductions can be made once appropriate learning processes are made from first-of-a-kind projects. Combining 'lessons-learned' with 'economy of scale' concepts is a furt her driving force for significant cost reduction. By analogy, significant reductions in the levelized energy cost have been seen for e.g. photovoltaic (PV) solar and onshore/offshore wind energy production. The costs drop over time and as more projects are installed. The Bloomberg global overview (BloombergNEF, 2020) indicates costs of 4-5 cents per $\mathrm{kWh}$ and 5-8 cents per $\mathrm{kWh}$ for wind and PV, respectively, however, large regional and caseto-case variations are seen. For economic comparison with tight oil production one may assume production costs of $50 \$ / \mathrm{bbl}$ of crude oil. Break even costs have been reported between 20 and 95 $\$ / \mathrm{bbl}$ (Kleinberg, 2018). The energy contained in crude oil is approximately $1600 \mathrm{kWh}$ per barrel (see e.g. NorskPetroleum, 2020) yielding an energy production cost of around 3 cents per $\mathrm{kWh}$ (the energy in crude oil varies greatly, but so does the oil-price). Further costs are added associated with a) refinery and transportation, b) reduced efficiency of burning fossil fuel compared to e.g. electric vehicles for transportation, and c) the costs associated with societal climate adaptation, imply that for tight oil production to be at economic advantage, costreduction during production is required. $\mathrm{CO}_{2}$ injection for EOR/EGR, and the proper incentives can contribute to the overall economics.

There is a growing public concern, and demand, for policies and market incentives to reduce emissions of $\mathrm{CO} 2$ globally. Tax incentives. such as the Euronean Union Allowance $\mathrm{CO}_{2}$ scheme 
and the 45Q in the US, have modified the $\mathrm{CO}_{2}$-EOR market towards the usage of anthropogenic sources. But they are not yet sufficient to cover the gap between the cost of 
capture and transport and the value created from EOR. This could change, should the market turn as much that the oil-field operator will get paid to deal with $\mathrm{CO}_{2}$ as a waste product for storage, instead of paying for $\mathrm{CO}_{2}$ for EOR purposes. Innovative solutions and new market incentives are needed today to make sure fair and transparent cash flows occur in a $\mathrm{CO}_{2}$ value chain where the same product may at the same time be both a value for utilization/EOR and as a waste product to be stored. As a corner stone in such economic systems lay the tight reservoir rocks, that may serve both as targets for $\mathrm{CO}_{2} \mathrm{EOR}$ and safe storage. Basic scientific knowledge on how $\mathrm{CO}_{2}$ mobilizes oil and gas, and how much of it remains trapped is key to develop such business models.

This Special Issue has aimed to improve understanding between $\mathrm{CO}_{2}$ and mobilization of hydrocarbons in different geological tight rocks and settings. The publications cover experimental, machine learning, simulation and review works and span a variety of topics including gas adsorption, in-situ monitoring of $\mathrm{CO}_{2}$, geological characterization of potential storage sites, carbonated water injection, $\mathrm{CO}_{2}$ foam rheology and leakage detection during CCUS operations. The results have potential usefulness for a global industry, as innovation, technological developments and scientific understanding are linked. In total 14 papers are published. A summary of the articles is presented in the following, sorted alphabetically by first author.

\section{Article summaries}

2.1 Fluid flux throughout matrix-fracture interface: Discretizing hydraulic fractures for coupling matrix Darcy flow and fractures non-Darcy flow.

Al-Rbeawi and Owayed (2020) present a semi-analytical model that couples matrix Darcy flow and hydraulic fracture non-Darcy flow using trilinear dual porosity and discretizing hydraulic fractures to several segments with a specific fluid flux. The model is verified against existing analytical and numerical solution and then a semi-analytical multilinear flow regime is developed for the pressure distribution. The results indicate that discretizing hydraulic fractures to several segments may give different pressure behavior, flow rate, and productivity index than single segment fracture.

\subsection{Modeling viscosity of $\mathrm{CO}_{2}$ at high temperature and pressure conditions.}

Amar et al. (2020) applied Machine Learning (ML) to predict $\mathrm{CO}_{2}$ viscosity modelled as function of temperature and density. Accurate prediction of $\mathrm{CO}_{2}$ flow properties is important in CCUS scenarios. Multilayer perceptron (MLP), gene expression programming and group method of data handling were implemented using 1124 experimental points covering temperature from 220 to $673 \mathrm{~K}$ and pressure from 0.1 to $7960 \mathrm{MPa}$. Four backpropagation techniques were used for MLP training. The trained MLP model outperformed preexisting ML models for $\mathrm{CO}_{2}$ viscosity. The GEP explicit correlation was superior to preexisting explicit correlations.

\subsection{Estimation of adsorption capacity of $\mathrm{CO}_{2}, \mathrm{CH}_{4}$, and their binary mixtures in Quidam shale} using LSSVM: Application in $\mathrm{CO}_{2}$ enhanced shale gas recovery and $\mathrm{CO}_{2}$ storage.

Least Squares Support Vector Machine (LSSVM) optimized by Particle Swarm Optimization, was used by Bemani et al. (2020) to learn and predict gas adsorption capacity in shale. 348 data points of pressure, temperature, gas composition and TOC were studied considering methane and carbon dioxide adsorption from pure and binary gas mixtures onto Jurassic shale samples from 
the Qaidam Basin in China. Model predictions on the training and validation datasets of $\mathrm{CO}_{2}$ and $\mathrm{CH} 4$ adsorption showed excellent match: for $\mathrm{CO}_{2}$ the coefficients of 
determination were 0.9990 and 0.9982 for training and validation datasets, respectively and for $\mathrm{CH} 4$ they were 0.9980 and 0.9966 .

\subsection{Explicit tracking of CO2-flow at the core scale using micro-Positron Emission Tomography $(\mu P E T)$.}

This paper by Brattekås and Haugen (2020) presents in-situ imaging of $\mathrm{CO}_{2}$ flow, utilizing highresolution micro-Positron Emission Tomography and radioactive tracer $11 \mathrm{C}$ carbon dioxide to explicitly track $\mathrm{CO}_{2}$ during dynamic flow and trapping. Unsteady state water injection (imbibition) and $\mathrm{CO}_{2}$ injection (drainage) were performed in a low-permeable chalk core at elevated pressure. Local flow patterns and dynamic spatial fluid saturations were determined. The presence of $\mathrm{CO}_{2}$ reduced water flow in high-permeability areas, promoting ideal displacement. Residual $\mathrm{CO}_{2}$ was evenly distributed after water injection, occupying $40 \%$ of the pore volume. Information obtained from in-situ saturation distributions may provide insights to constrain models and determine important flow mechanisms.

\subsection{Parametric uncertainty analysis for $\mathrm{CO}_{2}$ sequestration based on distance correlation and support vector regression.}

Cao et al. (2020) investigated the role of uncertain parameters on the response of $\mathrm{CO}_{2}$ injection for storage via the impact on simulated geomechanical and hydrogeological parameters. Distance correlation and machine learning support vector regression (SVR) were applied. A risk factor is introduced combining brittleness and stress increment to assess the potential risk of caprock integrity. The order of importance of parameters on fluid pressure and deformation at critical locations are obtained. Such analysis may assist to detect and prevent leakage events.

\subsection{Experimental study on rheological properties of nanoparticle-stabilized carbon dioxide foam.}

The rheological properties of nanoparticle (NP) stabilized $\mathrm{CO}_{2}$ foam with surfactant ( $\alpha$-olefin sulfonate-AOS) solution were experimentally investigated by $\mathrm{Du}$ et al. (2020). Relationships between shear stress, shear rate and apparent viscosity of foam and foam quality were determined under influential parameters including the NP additive, internal gas type, salinity, and oil presence. Critical foam quality in the range $91-96 \%$ were observed for NP-stabilized foam, whereas no such values were obtained for AOS-CO2 foam. The NP-AOS-CO2 foam has lower viscosity compared to NP-AOS-N2 foam. Solution salinity decreases the viscosity of the NP-AOS-CO2 foam. A more favorable rheology of injected $\mathrm{CO}_{2}$, by means of foam, may help to maintain the $\mathrm{CO}_{2}$ underground while hydrocarbons are produced.

\subsection{Population-balance modeling of $\mathrm{CO}_{2}$ foam for CCUS using nanoparticles.}

Eide et al. (2020) present a work where nanoparticle (NP) stabilized $\mathrm{CO}_{2}$ foam flow in porous media is modeled by tracking bubble density of NP foam spatially and temporally using an established surfactant (SF) population-balance model. A reduced shear-thinning effect is suggested, compared to SF, to accurately model NP $\mathrm{CO}_{2}$ foam flow in both high- and lowquality regime. A NP foam rheological transition appeared at gas fraction 0.85 , most prominent at low flow rates. The bubble density increased linearly with distance from inlet, with reduced $\mathrm{CO} 2$ mobility and improved displacement efficiency compared to co-injections of water and $\mathrm{CO} 2$. Improved understanding of how $\mathrm{CO} 2$ foam is transported will contribute to optimize 


\subsection{Impact of rock properties and wettability on Tertiary-CO2 flooding in a fractured composite chalk reservoir.}

This study by Ghasemi et al. (2020) presents experimental and numerical evaluation of tertiary$\mathrm{CO} 2$ flooding (CF) using reservoir and outcrop composite chalk at reservoir conditions (258 bara and $110^{\circ} \mathrm{C}$ ). A composite core $\mathrm{w}$ as used, consisting of six plugs of $7.5 \mathrm{~cm}$ each with a central hole with diameter $0.6 \mathrm{~cm}$. The core plugs are sampled from North-Sea-Chalk (NSCF) and saturated with NSCF stock tank oil and synthetic connate water. Sea water is injected. After no additional oil is observed, $\mathrm{CO}_{2}$ is injected. Compositional numerical simulation with a tuned equation of state (EOS) was developed to model the experiments. As many fields already are flooded with seawater for years, tertiary $\mathrm{CO}_{2}$ is especially important to understand as a final step when producing the last oil and converting reservoirs to $\mathrm{CO}_{2}$ storage sites.

\subsection{Investigation of variation in shale gas adsorption capacity with burial depth: Insights from} the adsorption potential theory.

Huang et al. (2020) applied Polanyi theory and isothermal adsorption parameters to investigate variation in shale gas adsorption capacity with burial depth using data from two shale samples with TOC content of $4.00 \%$ and $4.51 \%$. Adsorption capacity was found to first increase and then decrease with burial depth. The burial depth corresponding to the maximum adsorption capacity was basically constant within the study area. The pressure coefficient had the most impact on the minimum adsorption potential, while the ground temperature gradient was the most influential factor on the burial depth of the maximum adsorption capacity, reaching $1080 \mathrm{~m}$. Adsorption is a key gas storage mechanism in shales and theoretical understanding of its variation with depth and temperature may help predict both storage and reserve potentials.

\subsection{Review of $\mathrm{CO}_{2}$ injection techniques for enhanced shale gas recovery: Prospect and challenges.}

Iddphonce et al. (2020) reviewed continuous $\mathrm{CO}_{2}$ injection, and huff-n-puff $\mathrm{CO}_{2}$ in shale based on simulation works and field pilots. Reservoir pressure gradient, competitive adsorption, flow dynamics, and shale properties were found controlling $\mathrm{CH}_{4}$ recovery and $\mathrm{CO}_{2}$ storage. Simulations were found often to be based on well connected fractures and homogenous shale. Future studies were advised to address $\mathrm{CO}_{2}$ reproduction during huff-n-puff, effects of moisture, injection-induced effects on shale matrix, $\mathrm{CO}_{2}-\mathrm{CH} 4$ competitive adsorption, flow dynamics of multicomponent gas, heterogeneity and analysis of flow in stimulated fractures.

\subsection{Review of experimental sorption studies of $\mathrm{CO}_{2}$ and $\mathrm{CH}_{4}$ in shales.}

Gas adsorption in shales affects gas storage potential. A review was conducted by Klewiah et al. (2020) of experimental gas adsorption works showing that $\mathrm{CH}_{4}$ and $\mathrm{CO}_{2}$ adsorption capacity in shales increases with organic matter content, maturity, clay content and pressure. The capacity of kerogen type appears to go as Type III > Type II > Type I. Moisture strongly binds to clays which can yield lower gas adsorption for moisture-equilibrated samples compared to dry ones. Adsorption is exothermic with heat of adsorption greater for $\mathrm{CO}_{2}$ than $\mathrm{CH}_{4}$ in shales. $\mathrm{CO}_{2}$ is therefore favorably adsorbed over $\mathrm{CH}_{4}$ and both gases adsorb less at increased temperature. Knowledge of parameters affecting adsorption can provide important input to estimate reserve and storage potentials based on spatially distributed physical properties. 
2.12 Effect of rock mineralogy on Hot-CO $\mathrm{C}_{2}$ injection for enhanced gas recovery.

Static adsorption and core flooding experiments were performed by Mahmoud et al. (2019) to quantify methane/ $\mathrm{CO}_{2}$ adsorption/desorption using different rocks at different temperatures and pressures. Shale, tight sandstone, calcite, and dolomite were used. For calcite, theoretical simulations were performed. Methane desorption increased when the temperature was raised and the gas recovery increased for different rocks with increasing temperature. The study demonstrates how different rock types have potential for gas adsorption to store gas and that can $\mathrm{CO} 2$ enhance gas recovery.

\subsection{Machine learning for surveillance of fluid leakage from reservoir using only injection rates and bottomhole pressures.}

A machine learning method is proposed by Singh (2019) for surveillance of fluid leakage during $\mathrm{CO}_{2}$ injection using a deconvolution response function of time-varying bottom hole pressure and injection rates from injection and monitoring wells. Leakage is detected by comparing a baseline response without leaks to observed responses. The method uses only injection rates and bottomhole pressure data and is independent of physical process parameterization. This method provides a useful tool for early detection of leakage and potentially communication between wells during $\mathrm{CO}_{2}$ storage operations and can contribute to prevent or limit pollution of surrounding formations.

\subsection{Petrophysical and mechanical properties of the lower Silurian perspective oil/gas shales of Lithuania.}

Šliaupa et al. (2020) perform a characterization of Lower Silurian organic rich shales of west Lithuania in terms of mineralogical, petrophysical and mechanical properties. Some measured parameters are evaluated as positive for oil/gas exploitation (low swelling, low erodibility, and low stiffness) or of moderate quality (brittleness). Some parameters have low quality of the investigated shales (e.g. low cation exchange capacity, low porosity). A full geological characterization is essential to assess the economic potential of future developments.

\section{Summary and acknowledgments}

The special issue has demonstrated a varied set of contributions including the potential of machine learning to accurately model and predict important properties or detect events, use of nanoparticles to stabilize $\mathrm{CO}_{2}$ foam, reviews of the state of the art regarding injection techniques and gas adsorption, in situ tracking of $\mathrm{CO}_{2}$, tertiary $\mathrm{CO}_{2}$ injection in carbonates and characterization of potential storage sites for $\mathrm{CO}_{2}$. All these publications have, from different perspectives, contributed with new knowledge that may facilitate $\mathrm{CO}_{2}$ storage or utilization for enhanced hydrocarbon recovery purposes in especially tight shales and carbonates. Finally, we would like to thank all authors, reviewers and editors who have contributed to the success of this special issue.

\section{References}

Al-Rbeawi, Salam, and Jalal F. Owayed. 2020. 'Fluid flux throughout matrix-fracture interface: Discretizing hydraulic fractures for coupling matrix Darcy flow and fractures non-Darcy flow', Journal of Natural Gas Science and Engineering, 73: 103061. 
Amar, Menad Nait, Mohammed Abdelfetah Ghriga, Hocine Ouaer, Mohamed El Amine Ben Seghier, Binh Thai Pham, and Pål Østebø Andersen. 2 020. 'Modeling viscosity of $\mathrm{CO}_{2}$ at high temperature and pressure conditions', Journal of Natural Gas Science and Engineering, 77: 103271. 
Bemani, Amin, Alireza Baghban, Amir H. Mohammadi, and Pål Østebø Andersen. 2020.

'Estimation of adsorption capacity of $\mathrm{CO}_{2}, \mathrm{CH} 4$, and their binary mixtures in

Quidam shale using LSSVM: Application in $\mathrm{CO}_{2}$ enhanced shale gas recovery and $\mathrm{CO}_{2}$ storage', Journal of Natural Gas Science and Engineering, 76: 103204.

Bloomberg NEF, https://about.bnef.com/blog/scale-up-of-solar-and-wind-puts-existingcoal-gas-at-risk/, 28. April, 2020 (Aquired 23. June, 2020)

Brattekås, Bergit, and Malin Haugen. 2020. 'Explicit tracking of $\mathrm{CO}_{2}$-flow at the core scale using micro-Positron Emission Tomography ( $\mu$ PET)', Journal of Natural Gas Science and Engineering, 77: 103268.

Cao, Cheng, Jianxing Liao, Zhengmeng Hou, Gui Wang, Wentao Feng, and Yanli Fang. 2020. 'Parametric uncertainty analysis for $\mathrm{CO}_{2}$ sequestration based on distance correlation and support vector regression', Journal of Natural Gas Science and Engineering, 77: 103237.

Du, Dongxing, Xu Zhang, Yingge Li, Di Zhao, Fei Wang, and Zhifeng Sun. 2020. 'Experimental study on rheological properties of nanoparticle-stabilized carbon dioxide foam', Journal of Natural Gas Science and Engineering, 75: 103140.

Eide, Øyvind, Martin Fernø, Steven Bryant, Anthony Kovscek, and Jarand Gauteplass. 2020. 'Population-balance modeling of $\mathrm{CO}_{2}$ foam for CCUS using nanoparticles', Journal of Natural Gas Science and Engineering: 103378.

Ghasemi, M., V. S. Suicmez, L. Sigalas, and D. Olsen. 2020. 'Impact of rock properties and wettability on Tertiary- $\mathrm{CO}_{2}$ flooding in a fractured composite chalk reservoir', Journal of Natural Gas Science and Engineering, 77: 103167.

Holditch, S. A. (2006). Tight gas sands. Journal of Petroleum Technology, 58(06), 86-93. Huang, Hexin, Rongxi Li, Zhenxue Jiang, Jian Li, and Lei Chen. 2020. 'Investigation of variation in shale gas adsorption capacity with burial depth: Insights from the adsorption potential theory', Journal of Natural Gas Science and Engineering, 73: 103043.

Iddphonce, Raphael, Jinjie Wang, and Lin Zhao. 2020. 'Review of $\mathrm{CO}_{2}$ injection techniques for enhanced shale gas recovery: Prospect and challenges', Journal of Natural Gas Science and Engineering, 77: 103240.

Kleinberg, R. L., S. Paltsev, C. K. E. Ebinger, D. A. Hobbs, T. Boersma. 2018. 'Tight oil market dynamics: Benchmarks, breakeven points, and inelasticities', Energy Economics, 70: 70-83. https://doi.org/10.1016/j.eneco.2017.11.018

Klewiah, Isaac, Dhruvit S. Berawala, Hans Christian Alexander Walker, Pål Ø Andersen, and Paul H. Nadeau. 2020. 'Review of experimental sorption studies of $\mathrm{CO}_{2}$ and CH4 in shales', Journal of Natural Gas Science and Engineering, 73: 103045.

Mahmoud, Mohamed, Ibnelwaleed Hussein, Giuliano Carchini, Reyad Shawabkeh, Mohammed Eliebid, and Mohammed J. Al-Marri. 2019. 'Effect of rock mineralogy on Hot-CO2 injection for enhanced gas recovery', Journal of Natural Gas Science and Engineering, 72: 103030.

Norsk Petroleum, Oljedirektoratet, https://www.norskpetroleum.no/kalkulator/omkalkulatoren/, Aquired 23. june, 2020

Seales, M. B., Ertekin, T., \& Yilin Wang, J. (2017). Recovery efficiency in hydraulically fractured shale gas reservoirs. Journal of Energy Resources Technology, 139(4). 
Singh, Harpreet. 2019. 'Machine learning for surveillance of fluid leakage from reservoir using only injection rates and bottomhole pressures', Journal of Natural Gas Science and Engineering, 69: 102933.

Šliaupa, Saulius, Saulius Lozovskis, Jurga Lazauski enè, and Rasa Šliaupien è. 2020. 'Petrophysical and mechanical properties of the lower Silurian perspective oil/gas shales of Lithuania', Journal of Natural Gas Science and Engineering, 79: 103336. 
